\title{
Energy security and liquid fuels in South Africa
}

\author{
Jabavu Clifford Nkomo \\ International Development Research Centre
}

\begin{abstract}
South Africa relies heavily on imported crude oil. Domestic sources and available substitutes alone cannot satisfy the country's current demand, resulting in imported crude oil accounting for over $90 \%$ of South Africa's requirements. This high level of dependence on imported crude oil exposes the economy to potential events that either interrupts supplies or leads to higher oil prices thereby undermining economic growth and development. Widening diversity of supply, demand-side measures and maintaining strategic inventories will strengthen energy security.
\end{abstract}

Keywords: vulnerability, security, dependence, diversification

\section{Introduction}

This paper focuses on energy security in South Africa. Oil is a major component of the energy mix, so that energy security in our context is about reducing vulnerability of and dependence on oil imports. Vulnerability arises from a number of factors, such as collusion among oil exporting countries and insufficient diversification, growing dependence on imported sources of oil, demand/ supply imbalance leading to exporter instability, and political instability of exporting countries. There are compelling reasons for South Africa as a net oil importer to be concerned with energy security. First, domestic oil production falls far short from meeting the country's requirements, and there are no economically and readily available substitutes to replace imported crude oil on a large scale. Second, oil resources are spatially concentrated in a few countries, and South Africa depends heavily (over $90 \%$ ) on outside sources for its oil imports, with $94 \%$ of its crude oil requirements in 2003 coming from three OPEC producers (SAPIA, 2003). Third, because of oil's key role in supporting economic growth and development, any conflicts, wars, production cutbacks or supply disruption by OPEC producers pose a threat to South Africa's oil imports with wide ramifications on social development and economic growth.

In what follows, I first discuss issues linked to demand and reliance on crude oil. I then devote attention to the cost of energy dependence. The final section looks at ways of addressing energy insecurity by focusing specifically on strategies such as widening diversity of supply, demand-side measures and maintaining strategic inventories.

\section{Demand and reliance on crude oil}

Crude oil accounts for about $17 \%$ of South Africa's primary energy needs (SANEA, 2003). About $86 \%$ of the crude oil imports come from three countries: Saudi Arabia (36\%), Iran (34\%) and Nigeria (16\%) in 2006. Figure 1 shows diversified sources of supply and fluctuations in crude oil imports and local production. Saudi Arabia's oil import shares have became dominant, rising from $10 \%$ in 1997 , overtaking Iranian imports by 1999 and rising to $46 \%$ in 2003 , and $36 \%$ in 2006. The share of Iranian imports, on the other hand, fell from $51 \%$ in 1997 to $33.7 \%$ in 2003 and 2006 . The Nigerian import share rose from 5\% in 1997 to $17 \%$ in 2003 and 2006. Crude oil imports from the rest of the sources fell from $33 \%$ in 1997 to $13 \%$ in 2006, while local production has fluctuated around $3.1 \%$. Payment for imported supplies is in US dollars. Purchases in US dollars imply that the Dollar-Rand exchange rates are very important to domestic price movements. A weaker Rand implies more money to purchase crude oil leading, in turn, to higher fuel prices.

Dependence on outside sources leaves South Africa vulnerable to factors beyond its control such as oil price shocks and supply disruptions due to political and other external factors. Price fluctuations result in a flow of foreign exchange resources to oil producers, which would otherwise be used to stimulate the economy. Oil prices have fluctuated, and the trend has been upward. Reasons behind price increases from 1973 to 2006 beyond South Africa's influence include: 


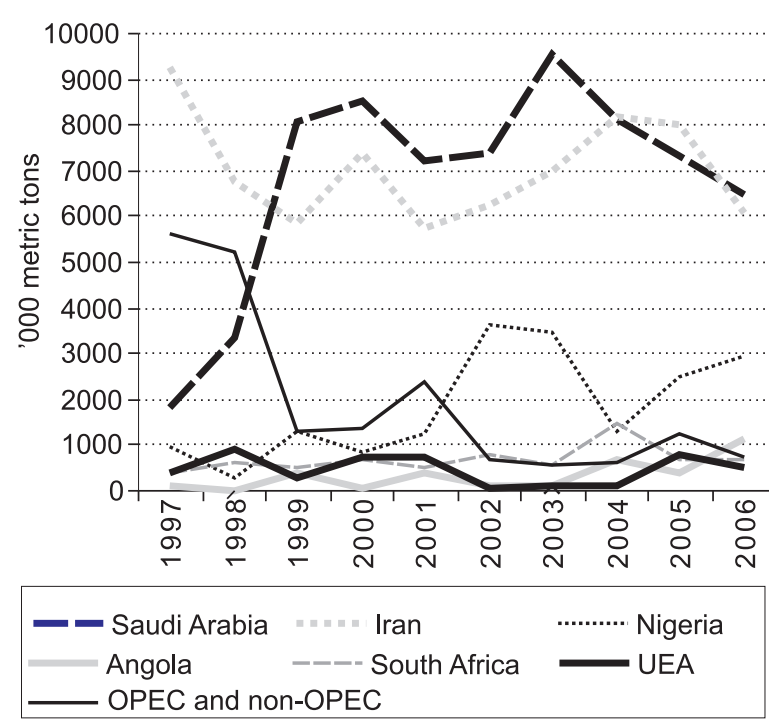

\section{Figure 1: South Africa's crude oil imports and own production, 1997 - 2006 \\ Source: SAPIA (2006)}

- The 1973/74 price shock. The price shock was both political and demand led (triggered by the Yom Kippur war and an Arab oil embargo, which included South Africa). World demand had been growing by $7.7 \%$ since 1965 , and oil prices quadrupled. The use of oil as a weapon at this time demonstrated that it was a blunt instrument that cannot be applied in a focused manner. The economies of both embargoed and untargeted oil-importing countries were negatively affected, and oil importing developing countries suffered more adverse economic impacts than the rich industrialized states. The inflation and monetary instability that followed affected South Africa.

- The $1979 / 80$ price spike that was politically driven, and triggered by the Iranian revolution in 1979. Prices tripled. In consequence, many central banks raised interest rates contributing to international recession.

- The 1990/91 price spike. The price spike was brief, following the Iraqi invasion of Kuwait, and collapsed not long afterwards with the invasion of Iraq. South Africa was already facing a downturn in economic activity because of a combination of factors such as weak demand of exports, its tight monetary policy, early phases of domestic drought, and political uncertainty.

- The September 112001 attack that sent prices rocketing.

- Demand led growth of other economies. Prices trebled between 2003 and 2006. The price rise was demand led and mainly attributable to global economic growth led by China - fuelled inflation, led to an interest rate tightening cycle, and contributed in the fall in economic growth.
Continued increase in prices threatened a reduction in disposable income, household consumption spending and a rise in second-round inflation.

There is debate in the literature about the nature of the current price of oil. One school of thought is that these prices are of a cyclical nature because of reversible factors pushing in the same direction. The other school of thought is that contrary to being cyclical, the oil prices are structural and reflect insufficient investment over the past years (Stevens, 2004). The important point to note is that if the current prices are cyclical they will eventually go down, and that they will remain high if they are structural. Either way, stability of oil prices at acceptable levels is crucial in securing supply. Even with stable price increases, following Hornsell's (1999) contention, the price of oil adjusts upwards (or is sticky) and balances supplies.

Demand for oil is demand inelastic in the medium term for reasons that there are no immediate substitutes for oil and consumers do not have flexibility to switch to other fuels. High crude oil is imported exposing South Africa to a number of events that could either interrupt supplies or lead to higher oil prices thereby undermining economic growth and development. If South Africa is to maintain a cogent energy security plan, the following issues deserve serious attention:

- Access to reliable, affordable, clean, sufficient and sustainable sources of energy to meet demand at affordable prices;

- Promotion of diverse energy resources; and

- Promoting sustainable development in energy planning. By creating a link between supply and demand, key consideration should be on economic growth, poverty alleviation, and promoting environmental integrity.

\section{The cost of dependence}

Oil dependence has its costs. The domestic economic impact of higher crude oil price changes, holding other factors constant, is predictable. Oil price increases the cost of liquid fuel relative to other factors as an input in production, squeezes the margins of companies, and leads to transfer of income to the oil exporting country through shifts in the terms of trade. Excessive price increases or oil 'price shocks' exacerbate the macroeconomic disruptions caused by oil price shocks. This causes dislocation in some sectors of the economy, reduces real national income of the importing country, and leads to a reduction in aggregate demand for goods. The magnitude of these effects, however, depends on the degree of dependence and the oil price elasticity of demand. The resulting speed of adjustment - often dictated by the real wage, price and structural rigidities in the economy - adds to 
the direct income effect of the oil price increase, with higher prices triggering inflation, increased input and transport costs in the economy and, ultimately, lower investment. All this compromises economic growth. Bacon (2005), for example, estimates that the average impact of a US $\$ 10$ a barrel price increase translates to a shock lowering the GDP by $0.8 \%$, and increases inflation by $1.2 \%$. While Bacon's estimates are in aggregate terms, the impact would be more revealing with disaggregated estimates of different end users, particularly the transport sector.

Table 1 shows South Africa's degree of oil dependence and the oil intensity of the economy. Energy intensity, the energy use per dollar of GDP or the amount of energy needed to support economic activity. High energy intensity is mainly because of the energy intensive activities within the economy, and implies the potential for improvement in efficiency. The degree of energy intensity is an indicator of vulnerability, and a high intensity implies the economy is more vulnerable to oil price increases. A plot of energy intensities from 1994 to 2003 reveals a negative trend line for South Africa, indicating a potential for both efficiency improvements and for keeping vulnerability down. Oil fuel dependence, on the other hand did not change between 1997 and 2003, precluding expectations of large changes in the medium term. However, the constant trend over time (see Table 1) may indicate absence of or limited input substitution taking place. The overall conclusion from Table 1 is that there is little prospect of South Africa reducing its import dependence at least, in the medium term.

Table 1: Oil vulnerability in South Africa Calculated from International Energy Agency publications

\begin{tabular}{lccc}
\hline & 1997 & 2000 & 2003 \\
\hline Energy intensity & 35858 & 36000 & 35348 \\
\hline Oil dependence & $20 \%$ & $20 \%$ & $20 \%$ \\
\hline Oil vulnerability & $52 \%$ & $56 \%$ & $55 \%$ \\
\hline Oil import dependence & $100 \%$ & $94 \%$ & $94 \%$ \\
\hline
\end{tabular}

Notes:

Energy intensity $y=$ total primary energy consumption per dollar of gross domestic product

Oil dependence computed as ratio of petroleum consumption to total primary energy consumption

Oil vulnerability calculated as (oil consumption - oil production)/oil consumption

Oil import dependence $=$ (net oil imports/oil consumption)

\section{Addressing energy insecurity}

There are various approaches to the problem of energy security. One view is that energy security should focus on the proper functioning of the economy, with uninterrupted availability of the energy resource at an affordable price (EU, 2000). In line with this view, the policy objective of security of supply is to reduce risks linked to dependence rather than attempting to maximize energy self-sufficiency or minimizing dependence. Another view accepts dependence on imports, but advocates for diverse sources of supply with no dominant supplier, enabling the economy to produce sufficient goods and services affordably (Egenhofer et al., 2004). In yet another approach, the IEA (2001) places responsibility on governments to reduce the risk of supply disruptions. While I consider these various approaches to be complementary, I now address the issue of minimizing disruptions of supply by focusing specifically on the following: widening diversity of supply, demand-side measures and maintaining strategic inventories.

\section{Widening diversity of supply}

Given how vital oil is to the functioning of the economy, any form of instability or disruption of supply may affect production costs, the purchasing power of private consumers, investment, and possible social conflict. One of the solutions to the problem to widen domestic sources of energy is to replace, in part, the supply of lost oil, and/or to decrease demand for oil from external sources and thus reduce the impact of oil price increases.

Widening diversity of supply involves developing domestic resources and diversifying fuel types. High global oil prices make domestic potential investments attractive, provide an incentive to develop known but previously uneconomic resources, and encourage exploration. Figure 2 provides a link between supply and demand by showing South Africa's diverse energy resource flows, and their transformation (in refineries), transportation (road, rail and pipeline), and end uses. The energy sources shown offer some scope for substitution with liquid fuels particularly in industry and commerce, and the household sectors. The dominance of coal in the primary energy supply is clear, with recoverable reserves of $55000 \mathrm{Mt}$. Coal accounts for $95 \%$ of electricity production - South Africa is classified as "water stressed", and therefore has limited potential for hydropower - and $23 \%$ of liquid petroleum production. Coal and natural gas resources are converted to liquid fuels (petrol, diesel, paraffin and polymers) in Sasol and PetroSA refineries, and account for about $30 \%$ of the country's liquid fuel products. Products refined locally from imported crude oil meet the balance. Local refining capacity has increased from 651000 barrels/day in 1997 to 708000 barrels/day in 2006 (see Table 2). Coal is not currently viable to supply the entire country's liquid fuel demand from coalto-liquid fuel. 


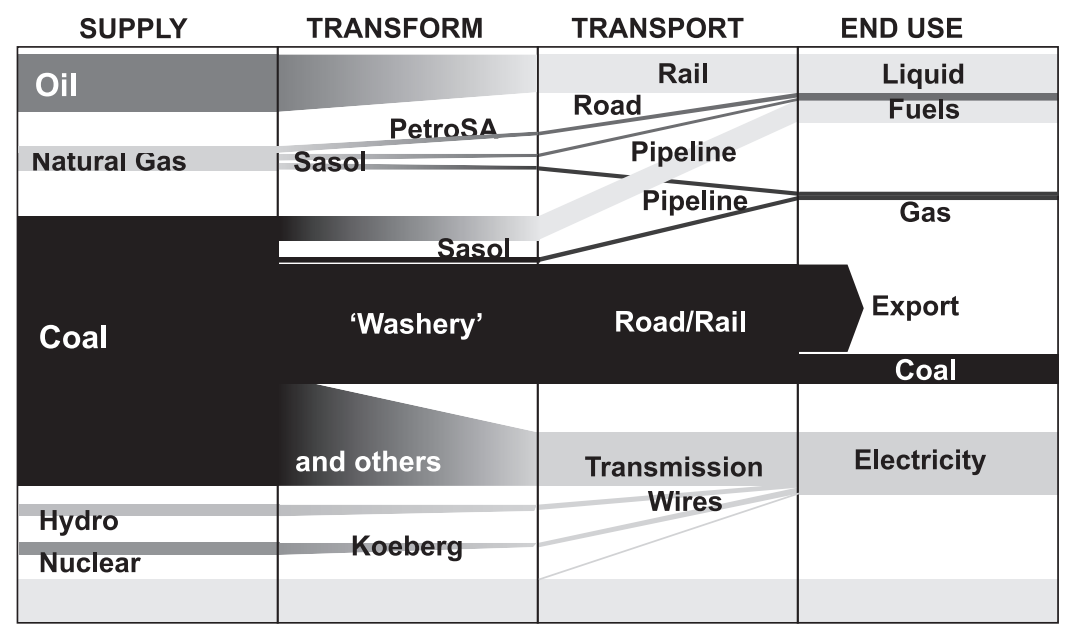

Figure 2: South Africa's energy flows

Table 2: Capacity of South African refineries (billion barrels/day)

Source: SAPIA (2006)

\begin{tabular}{lcrc}
\hline Refineries & 1992 & 1997 & 2006 \\
\hline Sapref & 120000 & 165000 & 180000 \\
\hline Enref & 70000 & 105000 & 125000 \\
\hline Calref & 50000 & 100000 & 100000 \\
\hline Natref & 78000 & 86000 & 108000 \\
\hline Sasol & $150000^{*}$ & $150000^{*}$ & $150000^{*}$ \\
\hline PetroSA & $45000^{*}$ & $45000^{*}$ & $45000^{*}$ \\
\hline Total & 513000 & 615000 & 708000 \\
\hline *Crude equivalent & & \\
\hline
\end{tabular}

South Africa has small but economically important offshore oil and gas resources. Oil in the Oribi/Oryx Oil Field and the Sable Oil Fields has proven reserves of 49 million barrels, and the Oribi/Oryx Oil Fields produced 4.6 million barrels in 2002 (SANEA, 2003). Production in the Sable Oil Field began in 2003. This source has the potential to replace $7 \%$ to $10 \%$ of the imported oil. Certified natural gas reserves are insufficient to justify a major switch to gas. F-A Field is the only gas field in production. With prospects of this gas field running out in 2008, explorations are underway in adjacent fields. The largest gas reserve, Ibhubesi Gas Field, is undergoing development, with other reserves off the West Coast under investigation. High oil prices should provide an incentive to develop these domestic opportunities and to reduce South Africa's vulnerability to increases in international oil prices.

\section{Demand-side measures}

Demand-side measures take into account policies that influence a real change in consumer behaviour. The objective of such policies can be multi-fold, but can be aimed at enhancing energy saving, promoting energy efficiency, reducing oil intensity, and maintaining stable prices. Fiscal measures - taxes and/or subsidies - tend to be effective since they work through the price system. The argument in support of petroleum taxation is that this restraint measure helps to steer demand towards better-controlled consumption and to conserve foreign exchange, it does not require a major administrative system, and it allows the market to allocate the petroleum products. Following this line of thinking, taxation discourages liquid fuel consumption, and triggers efficient energy use.

There are, however, problems associated with this approach. This measure alone cannot guarantee that private and diverse producers and consumers will react in a desired way. If demand is price-inelastic, given the short run fixity of energy consuming capital and constraints on energy consuming replacement appliances, reducing consumption will be limited as prices rise. There is always a danger that taxes on oil imports will increase production and consumer costs, act regressively in income redistribution, and risk reducing the competitiveness of the country's exports.

\section{Maintaining strategic inventories}

One way of circumventing disruptions to crude oil supplies is to maintain a strategic stockpile as a contingency against supply interruptions. Storing crude oil stocks instead of petroleum products offers several advantages: crude oil is cheaper to store, its quality is technically easier to maintain, and it provides flexibility in processing to products to meet demand during times of supply disruption. The strategic stockpile can be held and not to be allowed to run down beyond a target figure. The administrative and storage costs of such a policy is insignificant if one takes into account the opportunity cost of tied-up capital.

Given that inventories are costly to build, it makes sense to build them when oil prices are anticipated to increase at a rate greater than the opportunity cost of money. The cost of oil shortage to the economy is enormous. The DME (2006) estimates 
the cost of fuel shortage (using 2005 prices) to be 273 cents per litre, and at least R925 million a day. The larger the inventories held the less likely will be the damaging impact of any trade disruptions, since the inventory held can be used to mitigate and smooth erratic oil supply shortage, thereby minimizing security risks involved in import dependence. The strategic stockpile of oil reserves offers protection against a major supply disruption, but the scope and duration of this protection depends on the quantities held.

\section{Challenge}

Energy policy faces a challenge of achieving the goal of significantly lowering oil dependence from external sources and of reducing energy insecurity. Achieving these goals will not be easy and will take a long-term to accomplish. Indeed, there are supply and demand measures that are relevant in an attempt to reduce energy insecurity. However, these are not the only measures available to reduce the demand for imported oil. Other policy measures that promote conservation, energy efficiency and quantitative restrictions on imports affect the demand for imported crude oil are additional policy measures available.

Like other policy measures, it is important to pursue them efficiently and manage them centrally. Of preference is a method that works through the price system so that if the price on all oil rises, its effect, depending on the price elasticity of demand, will be to discourage consumption, encourage domestic supply and discouraging crude oil imports. Market forces, once allowed to play their part, allocate energy efficiently and simplify other aspects of energy policy. Issues of oil dependence, vulnerability and indigenous supply potential remain key concerns for energy policy, and demand strong emergency response measures.

\section{References}

ABSA 2004. Developments in the International oil market - implications for South Africa. Economic Perspectives. Third Quarter 2004.

Department of Minerals and Energy (DME) 2002. South Africa National Energy Balance 2002. Pretoria.

Department of Minerals and Energy (DME) 2006. Energy Security Master Plan -Liquid Fuels.

European Commission) 2000. Towards a European Strategy for the Security of Energy Supply. Green paper, COM (2000) 769.

http://www.europa.eu.int.comm/energy_transport/en/lpi lv_enl.html.

Egenhofer, C. Gialogou, K. Luciani, G. Boots, M. Scheepers, M. Constantini, V. Grecceva, F. Markandya, A. and Vicini, G. 2004 Market-based Options for Security of Energy Supply. International Energy Markets. September 2004.
www.feem.it/Feem/Pub/Publications/WPapers/default.htm. International Energy Agency (IEA) 2001. World Energy Outlook Insights 2001, IEA/OECD, Paris.

Energy Information Administration (EIA) 2004. International Energy Outlook. DOE/EIA Washington DC

Energy Information Administration (EIA) 2005. OPEC Revenues: Country Details. www.eia.doe.gov. January 2005

Farrell, G.N. Kahn, B. and Visser, F.J. 2001. Price Determination in International Oil Markets: Developments and Prospects. South African Reserve Bank Quarterly Bulletin. March 2001.

Hornsell, P. 1999. US Oil Security and the Oil Import Tariff Question. Oxford Energy Studies. Oxford Energy Comment.

Kohl, W.L. 2002. OPEC Behaviour, 1998-2001. The Quarterly Review of Economics and Finance, 42, 209-233.

Lajous, A. 2004 'Production Management, Security of Demand and Market Stability'. Paper presented at the OPEC International Seminar, Vienna. September 2004.

Lounnas, R and Brennand, G. 2002. Oil Outlook to 2020. Organization of the Petroleum Exporting Countries

Manzoni, J. 2005 BP's Views on options to Build Energy Security. www.bp.com/genericarticle.do?categoryld= $98 \&$ contentId $=7005588$

Mboweni, T. 2004. The State of the South African Economy. Address at the Annual Dinner in Hour of the Ambassadors and High Commissioners to the Republic of South Africa, Pretoria. 7 December 2004.

Quarterly Economic Review (QER) 2005. Quarterly Bulletin, South African Reserve Bank. June 2005.

Parry, I.W. and Anderson, J.W. 2005. Petroleum: Energy Independence is Unrealistic. Resources for the Future. Issue Number 156.

South African National Energy Association (SANEA) 2003. South African Energy Profile 2003. World Energy Council.

Standard Bank (SB) 2005. Solid Growth, but not without Risks. Economy Focus. 17 May 2005.

Skinner, R and Arnott, R. 2005. 'The Oil Supply and Demand Context for Security of Oil Supply to the EU from the GCC Countries'. Oxford Institute for Energy Studies

Stevens, P 2004. Future Price of Crude Oil. Middle East Economic Survey. Vol. XLII No 713 September 2004.

US Encyclopaedia of Energy - A History of OPEC. http://www.cges.co.uk/pdf-lib/otherpapersHistory ofOPEC31.pdf.

Wall Street Journal (WSJ) 2005. Rising Oil Prices Fail to Slake Thirst. See also the City Press, June 262005 page 17 .

Received 6 September 2005; revised 30 January 2009

Submitted by the author when employed at the Energy Research Centre, University of Cape Town. 